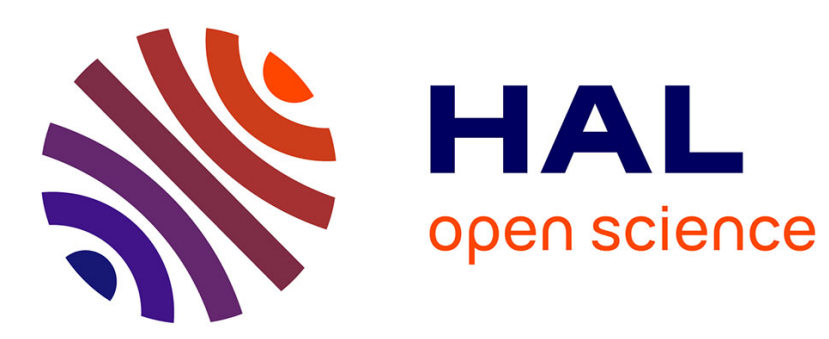

\title{
New Psychological Paradigm for Conditionals and General de Finetti Tables
}

Jean Baratgin, David Over, Guy Politzer

\section{To cite this version:}

Jean Baratgin, David Over, Guy Politzer. New Psychological Paradigm for Conditionals and General de Finetti Tables. Mind and Language, 2014, 29 (1), pp.73-84. 10.1111/mila.12042 . ijn_01295434

\section{HAL Id: ijn_01295434 \\ https://hal.science/ijn_01295434}

Submitted on 1 Apr 2016

HAL is a multi-disciplinary open access archive for the deposit and dissemination of scientific research documents, whether they are published or not. The documents may come from teaching and research institutions in France or abroad, or from public or private research centers.
L'archive ouverte pluridisciplinaire HAL, est destinée au dépôt et à la diffusion de documents scientifiques de niveau recherche, publiés ou non, émanant des établissements d'enseignement et de recherche français ou étrangers, des laboratoires publics ou privés. 
The definitive version is available at www.blackwell-synergy.com

\title{
New psychological paradigm for conditionals and general de Finetti tables
}

\author{
Baratgin, J., Over, D. \& Politzer, G.
}

\begin{abstract}
The new Bayesian paradigm in the psychology of reasoning aims to integrate the study of human reasoning, decision making, and rationality. It is supported by two findings. One, most people judge the probability of the indicative conditional, $\mathrm{P}($ if $\mathrm{A}$ then $\mathrm{B})$, to be the conditional probability, $\mathrm{P}(\mathrm{B} \mid \mathrm{A})$, as implied by the Ramsey test. Two, they judge if A then B to be void when A is false. Their three-valued response table used to be called 'defective', but should be termed the de Finetti table. We show how to study general de Finetti truth tables for negations, conjunctions, disjunctions, and conditionals.
\end{abstract}

Acknowledgements: Financial support for this work was provided by the French ANR agency under grant ANR Chorus 2011 (project BTAFDOC). We should also like to thank Thomas Charreau and Jean-Louis Stilgenbauer for much discussion and other help in our research, and two anonymous reviewers for helpful suggestions.

Address for correspondence: Jean Baratgin, Université Paris 8 (UFR de Psychologie), 2 rue de la Liberté, 93200 Saint Denis, France.

Email: jean.baratgin@univ-paris8.fr 


\section{Introduction}

Bayesian models of cognition have become increasingly prominent in the psychology of reasoning in recent years, and this trend has resulted in the development of a new Bayesian paradigm (Manktelow, Over, \& Elqayam, 2011; Oaksford \& Chater, 2007, 2009; Over, 2009; Pfeifer \& Kleiter, 2010). The older binary paradigm in the psychology of reasoning focused on deduction from assumptions. Propositions were classified as either true or false, or consistent or inconsistent with each other. Conclusions either followed necessarily or not at all. If the participants in a reasoning experiment did not assume the premises, but relied on their subjectively relevant beliefs, or they inferred conclusions that did not necessarily follow, they were deemed to be biased and to commit fallacies. This older paradigm inspired many theoretical models (mental rules, mental models, rules or schemas, and others) but limited the field of research to the study of the human deduction ability (Evans, 2012). The new paradigm recognizes that most inferences in everyday affairs and science, whether logically valid or not, are from uncertain beliefs or hypotheses and not assumptions, and that reasoning must take account of this uncertainty if it is to be useful for acquiring rational beliefs and making rational decisions. The basic goal of the new paradigm is to integrate the psychology of reasoning and the psychology of judgment and decision making and provide a full account of human reasoning, decision making, and rationality.

Consider the valid inference of Modus Ponens (MP), inferring $B$ from if $A$ then $B$ and

\section{$A$. Let if $A$ then $B$ here be:}

(1) If Italy leaves the Euro this year $(I)$ then the Euro will decline in value $(D)$.

We cannot make a rational decision about what to do with our Euros by simply assuming that if I then $D$ and that $I$, in order to infer $D$ by MP, that the Euro will decline in value. We must at least assess our degree of confidence in (1), P(if I then D), and the prediction that $I, P(I)$. 
We can then try to have a rational degree of belief in the conclusion of MP, $P(D)$, for our decision making. There was a significant step towards the new paradigm when experiments showed that people's confidence in the premises of conditional inferences does affect their confidence in the conclusions in systematic ways (George, 1995, 1997; Politzer, 2005; Politzer \& Bourmaud, 2002; Stevenson \& Over, 1995, 2001).

\section{The Equation And Restricted De Finetti Table}

The new paradigm was given an even greater boost by the finding in experiments that people judge the subjective probability of the natural language indicative conditional, $P($ if $A$ then $B$ ), to be the conditional probability of $B$ given $A, P(B \mid A)$. Philosophers have long argued for this relation between the conditional and conditional probability, $P($ if $A$ then $B)=P(B \mid A)$. It has been seen as so important normatively that it has simply been called the Equation (Edgington, 1995). Logical and philosophical support for it can be traced back to Ramsey (1926/1990) and de Finetti (1936/1995, 1937/1964), the founders of contemporary subjective probability theory (Politzer, Over, \& Baratgin, 2010). The Equation can be studied in probability tasks as the conditional probability hypothesis and has been confirmed for a very wide range of conditionals (Douven \& Verbrugge, 2010; Evans, Handley, Neilens, \& Over, 2007; Evans, Handley, \& Over, 2003; Fugard, Pfeifer, Mayerhofer, \& Kleiter, 2011; Oberauer \& Wilhelm, 2003; Politzer et al., 2010), including examples like (1) that could be called 'causal' conditionals (Over, Hadjichristidis, Evans, Handley, \& Sloman, 2007). Judging that $P($ if $A$ then $B)=P(B \mid A)$ is the majority response in these experiments. This strong confirmation of the conditional probability hypothesis provides substantial empirical support for a Bayesian account of conditional reasoning. The indicative conditional can be represented by the conditional probability and rational degrees of belief in conclusions of 
conditional inferences can be calculated from subjective probabilities for the premises (Adams, 1998; Gilio \& Over, 2012; Hahn \& Oaksford, 2007; Oaksford \& Chater, 2007, 2009; Over, Evans, \& Elqayam, 2010; Pfeifer \& Kleiter, 2010). A Bayesian account can also be applied to what have been called utility conditionals (Bonnefon, 2009).

An important point to note is that a significant number of participants on some probability tasks give the conjunctive response, $P($ if $A$ then $B)=P(A \& B)$, and not the majority conditional probability response, $P($ if $A$ then $B)=P(B \mid A)$. It has been found that participants who give the conjunctive response are of lower cognitive ability than the participants who respond with the conditional probability (Evans, Handley, Neilens, \& Over, 2007, 2010; Politzer et al., 2010). There is also a developmental trend: young children respond with the conjunctive probability, but this response tends to decline with age, and the conditional probability response increases until it becomes the majority response in undergraduate students (Gauffroy \& Barrouillet, 2009). The most recent finding, superseding earlier work, is that the conjunctive response tends to decline and be replaced by the conditional probability response as more probability tasks are done (Fugard et al., 2011). It is hard to see how people can make rational decisions if they think that $P($ if $A$ then $B)=P(A \&$ $B)$, but yet another point about this response is that it does not occur significantly for the most realistic conditionals like (1) and, for an example actually studied, 'If global warming continues then London will be flooded' (Douven \& Verbrugge, 2010; Over et al., 2007). More research is needed to understand fully, not only on the conjunctive response for conditionals, but also on how uncertainty affects judgments about conjunctions, disjunctions, negations, and conditionals more generally.

Another strong body of support for the new paradigm comes from experiments on truth table tasks and the discovery of what came to be called the defective truth table in psychology (see Evans \& Over, 2004, for review up to that date). If (1) were a material 
conditional (as in much of the older paradigm), (1) would be equivalent to not-I or $D$ and would be true when $I \& D$ is true, false when $I \&$ not-D is true, and true for the two false antecedent, not- $I$ cases, when not- $I \& D$ is true and when not- $I \&$ not- $D$ is true. However, participants in truth table task experiments diverged from this table in the false antecedent cases. They would say that these cases were 'irrelevant' for determining the truth or falsity of (1). More recently, participants have responded that the conditional is neither true nor false in these cases (Politzer et al., 2010). From a new paradigm point of view, these participants are not producing a 'defective' truth table in any negative sense. Psychologists in the old paradigm were apparently unaware that de Finetti $(1936 / 1995,1937 / 1964)$ had originally proposed this three-valued table on normative grounds (there are no references to de Finetti in psychological work on the 'defective' truth table up to and including the survey of Evans \& Over, 2004, but see Politzer et al., 2010). Given the 'defective', de Finetti table, the indicative (1), and its past tense equivalent, will become void and without truth value should Italy not leave the Euro this year, although there could then be grounds for a counterfactual about what would happen if Italy were to leave the Euro, or what would have happened if it had left the Euro (see Over et al., 2007, on the relation between counterfactuals and the conditional probability).

The finding that people judge that $P($ if $A$ then $B)=P(B \mid A)$ raises the question of how they process conditionals to produce this result. Most psychologists in the new paradigm again follow philosophers in holding that people use the Ramsey test to evaluate conditionals (Ramsey, 1926/1990). As modified by later philosophers, the Ramsey test is a process in which people assess $P$ (if $A$ then $B$ ) by hypothetically supposing $A$, making whatever changes are necessary to preserve consistency, and then judging the probability of $B$ given this supposition (Edgington, 1995; Evans \& Over, 2004; Stalnaker, 1968). The result of this process is that $P($ if $A$ then $B$ ) is the probability of $B$ given $A, P(B \mid A)$. A conditional if $A$ then $B$ 
with the property that $P($ if $A$ then $B)=P(B \mid A)$ has been called a probability conditional (Adams, 1998; Oaksford \& Chater, 2007) and the conditional event (de Finetti, 1936/1995, 1937/1964; Pfeifer \& Kleiter, 2010). We will use both of these expressions in this paper for this conditional, but will favour 'conditional event', symbolized by de Finetti as B $\mid \mathrm{A}$, later in the paper when we are focusing primarily on de Finetti's proposals.

For an account of the natural language indicative conditional, the probability conditional has many advantages over the material, truth functional conditional, logically and psychologically. In particular, the probability conditional does not suffer from the 'paradoxes' of the truth functional analysis of the natural language conditional (Edgington, 1995; Evans \& Over, 2004; Oaksford \& Chater, 2007; Pfeifer \& Kleiter, 2010). As an example of one of these paradoxes, consider (1), if I then $D$, and the result of negating its consequent, if I then not-D. Rational decision making about what to do with our Euros partly depends on the fact that $\mathrm{P}($ if I then $D)$ is very high while $\mathrm{P}($ if I then not- $D)$ is very low, and similarly for the corresponding conditionals about France and Germany. However, if these were truth functional conditionals, and so true when their antecedents were false, they would all become more probable as it became more and more likely that Italy, France, and Germany would not leave the Euro by the end of the year. This absurd result does not follow if these conditionals are probability conditionals, and virtually no one in experiments (see most recently Fugard et al., 2011) judges that $P($ if $A$ then $B$ ) is the probability of the material conditional, $P($ not $-A$ or $B)$.

The probability conditional, conditional event also has an advantage over other nontruth functional theories of the conditional, such as that of Stalnaker (1968). Lewis (1986) proved that 'triviality results' follow from assuming that $P($ if $A$ then $B)=P(B \mid A)$ for conditionals like Stalnaker's, which are true or false at every possibility. His proof does not apply to the conditional event, which is void and has a truth value gap when its antecedent is 
false (a fact that Lewis was well aware of; see Mura, 2009, and Paneni \& Scozzafava, 2003, as well as Lewis, 1986). And as we have reported above, the evidence is strong, from psychological results on the 'defective', de Finetti table, that people consider indicative conditionals neither true nor false when their antecedents are false. Nevertheless, it is also theoretically possible to avoid the triviality results by holding that people's interpretations of conditionals depend on their belief states (van Fraassen, 1976). This theoretical position does not imply that an underlying binary view has to be given up and has other possible advantages (Douven \& Dietz, 2011; Douven \& Verbrugge, under review). It could be argued, however, that the de Finetti table is a better explanation of 'defective' responses in truth table tasks.

There is an important point of agreement among Adams, de Finetti, Lewis, Stalnaker, and van Fraassen. They all hold that if $A$ then $B$ is true when $A \& B$ is true. No epistemic or other connection is required between $A$ and $B$ as a matter of semantics, although such a connection could be a reasonable pragmatic expectation. Some psychological experiments are relevant to this position, but it is still unclear whether people consider if $A$ then $B$ to be false, or only pragmatically infelicitous, when there is no connection between $A$ and $B$ and so $A$ does not raise the probability of $B$ (Over et al., 2007; Douven \& Verbrugge, in press).

The 'defective', de Finetti table has received far less attention than the Equation in the new paradigm (but see Evans et al., 2007, on the close relation between conditional probability judgments for the conditional, 'defective' responses on truth table tasks, and relatively high cognitive ability, and also Sevenants, Dieussaert, \& Schaeken, 2011, on truth table tasks and cognitive ability). Given the negative connotations of the term 'defective', it is better to call this three-valued table simply the de Finetti table (Politzer et al., 2010). In fact, we should use restricted de Finetti table for the 'defective' truth table, since de Finetti (1936/1995) actually proposed what we will call general de Finetti tables, not only for the 
conditional event, but for negation, conjunction, and disjunction. See Appendix 1. In these tables, $A$ and $B$ can receive a third value. We will explain later in this paper how to give people general truth table tasks, which have a third value for $A$ and $B$, and to study for the first time whether these match de Finetti's more general tables.

Another much neglected topic in the new paradigm, which is related to both the Equation and the de Finetti table for the conditional, is the conditional bet. Both Ramsey $(1929 / 1990)$ and de Finetti $(1937 / 1964,1974)$ justified their normative theories of subjective probability by referring to bets that were to represent degrees of beliefs. Conditional bets, representing conditional degrees of belief, were central to their theories. The fundamental result is that people who violate normative probability theory, and so are incoherent, are irrational because they are vulnerable to a Dutch book: a series of bets that can only be lost (de Finetti, 1974; Gilio \& Over, 2012). A conditional bet can be seen as a bet on the conditional event, and the new paradigm implies that there should be a close relation between a degree of belief in an indicative like (1) and a willing to express a conditional bet like: (2) I bet that, if Italy leaves the Euro this year $(I)$, then the Euro will decline in value $(D)$. There is clearly a parallel relation between the three-valued de Finetti truth table for (1) and the de Finetti winning table for (2). By these tables, (1) is true and the bet (2) is won when I $\& D$ is true, (1) is false and (2) is lost when $I \&$ not- $D$ is true, and (1) is void and neither true nor false, and (2) is void and neither won nor lost in the not- $I$ cases. Moreover, the probability that assertion (1) is true and the probability of winning the bet (2) should both be $P(I \& D \mid I)$ $=P(D \mid I)$, since there is no assertion to be true and no bet to be won in the not- $I$ cases (for a theoretical analysis of logico-algebraic structure see Milne, 1997). Politzer et al. (2010) have found evidence that people conform to this parallel relationship for a simple indicative conditional and a conditional bet (see also Oberauer \& Wilhelm, 2003, for the only other psychological paper on bets about conditionals). 


\section{General De Finetti Tables}

There is, however, a serious limitation in all the experiments that have been run so far on the 'defective' truth table. The participants have always been given a conditional, if $A$ then $B$, and then asked about its evaluation for one of the four possible cases, $A \& B, A \&$ not- $B$, not- $A \&$ $B$, and not- $A \&$ not- $B$, which has always been described or displayed clearly and without any uncertainty. For example, if such an experiment were actually run about (1) and (2), the participants might be told, say, that Italy was not going to leave the Euro by the end of the year and the Euro was not going to decline in value, a not-I \& not-D case, and then asked how (1) and (2) were to be evaluated. The answer would of course be (on past evidence) that (1) is neither true nor false and (2) neither won nor lost. But the point is that it is unrealistic, and in considerable tension with the whole new paradigm approach, to suppose that we are often absolutely certain of which possible case holds for the evaluation of a conditional. We are much more often in a state of uncertainty about such matters as whether or not Italy will leave the Euro by the end of the year $I$ and whether or not the Euro will decline in value $D$. We are consequently uncertain about (1) and have a degree of belief $P(D \mid I)$ about it that is less than 1 . The new paradigm is all about uncertainty in our reasoning and how this affects rational inference and decision making. General truth table tasks should therefore be developed that reflect all this uncertainty.

There is fortunately help in the normative literature for a psychological project of developing more realistic truth table tasks. As we have already noted, de Finetti (1936/1995) constructed general tables for negation, conjunction, and disjunction, and the conditional event, and in these tables, the two basic propositions, $A$ and $B$, can be true, false, or have a third value void. For these general tables, the third value can be interpreted as uncertainty in a wide sense and not just as a 'void' sense of neither true nor false. In this interpretation, the 
general tables for negation, conjunction, disjunction and material conditional correspond to strong Kleene connectives (Haack, 1974). The de Finetti general tables were actually proposed by Blamey (1986) in his semantic analysis of partial logic (see for a discussion Mura, 2009), although Blamey did not refer to de Finetti. The de Finetti conditional table also corresponds to the table for the presupposition operator proposed by Beaver (1997). If 'uncertain' means 'unknown', then it is possible that binary values underlie it (and so the approach of Douven \& Dietz, 2011, Douven \& Verbrugge, under review, and van Fraassen, 1976, could be taken).

We will now outline one way to develop research on these general de Finetti tables. Consider an extension of the Politzer et al. (2010) study. They gave participants an indicative conditional and a conditional bet about a chip selected at random from an array of square and round chips that were black or white:

(3) If the chip is square (S) then it is black (B).

(4) I bet you 1 Euro if the chip is square (S) then it is black (B).

The participants could then be asked whether the selection of, say, a round and black chip, not-S \& B, made (3) true, false, or neither true nor false, and meant that (4) was won, lost, or neither won nor lost. There was no doubt or uncertainty in this experiment about whether the randomly selected chip was square or black. But consider how some uncertainty could be introduced. As well as letting the participants look carefully at the randomly selected chip in good light, there could also be the possibility of letting the participants only get a glimpse of the chip or seeing it in bad light. Now the two basic propositions, here $S$ and $B$, could be true, false, or have a third value of uncertainty. Suppose the participants were able to see the chip for long enough to be sure that it was square, but the light was so bad that they were uncertain whether it was black or white. With $S$ true and $B$ uncertain, how would the participants evaluate (3), as true, false, or uncertain? If they conformed to the general de Finetti table for 
the conditional event, they would evaluate (3) as uncertain in this case. If they also conformed, in this case, to the general de Finetti tables for negation, conjunction, and disjunction, they would evaluate not- $B$ as uncertain, $S \& B$ as uncertain, but $S$ or $B$ as true. And they would have parallel evaluations in terms of winning, losing, and uncertainty about (4) and about bets on not-S, $S \& B$, and $S$ or $B$.

Seeing chips more or less quickly in good or bad light might be a reasonable model of some natural circumstances. It would, however, be too hard to construct and control an experiment of exactly this type. What we did was to create a computer representation of two opaque boxes, one on top of the other, with some open and clear space between them. The top box had square or round chips in it that were black or white. Random chips could at times fall from the top box to the bottom box, and then a photo would be taken of these chips in the space between the boxes. The photos were sometimes taken through filters, which could have the effect of concealing the shape or colour of the chips, or both the shape and the colour. The participants were told that children were playing a game about the chips that fell from the top box to the bottom box. One of the children made an assertion about the random chips. We will report here data on the cases in which the child's assertion was an indicative conditional, (3), a conditional bet, (4), or a negation, not-S, conjunction, $S \& B$, or disjunction, $S$ or $B$. For example, if the child asserted (3) or (4), and the filter allowed the photo to show a square chip without revealing its colour, then we would have a case like the one that we have described above, when a square chip could be seen but bad light concealed the colour.

Thus in our general truth table task, participants were presented with nine possible photos - $S$ and $B$ true, false, or uncertain - and were asked to say in each case whether an assertion (or conditional bet) by the child was true (won), false (lost), or neither true (won) nor false (lost). The participants' responses allowed us to construct tables for them for the five different assertion forms that we are considering here - negation, conjunction, 
disjunction, the indicative conditional, and the conditional bet. The main finding was that a large majority of participants complied with the general de Finetti tables. Most participants responded with the conditional event table for the child's assertion of the indicative conditional and also of the conditional bet (with $\mathrm{T}$ interpreted as winning, $\mathrm{F}$ as losing, and $\mathrm{U}$ as neither winning nor losing). For the child's assertion of a negation, not-S, almost all participants produced the de Finetti table for negation. Similarly, for child's assertion of a conjunction, $S \& B$, slightly more than three quarters of the participants responded with de Finetti's table. This proportion increased to near totality when the answers that differed from de Finetti's conjunction table by a single cell were included (that is, when a single error out of nine answers is allowed). Finally, for the child's assertion of a disjunction, $S$ or $B$, a large majority of participants conformed to de Finetti's table.

\section{Conclusion}

Research on de Finetti's general three-valued tables, which allow for uncertainty in the components of conditionals, negations, conjunctions, and disjunctions, has been totally neglected in the psychology of reasoning, but we hope to have indicated here how to overcome this limitation. Of course, we are well aware that many three-value tables have been proposed by other logicians, philosophers, and AI researchers (see the Appendix of Haack, 1974, for a good display of a wide range of tables in the literature up to that date and Goodman, Nguyen \& Walker, 1991, for more recent tables). Milne (in press) also points out that logical validity can be defined in terms of probability, as suggested by the Equation (Edgington, 1995, Adams, 1998), or directly in terms of preserving values in de Finetti or other tables, and that these two types of definition validate different patterns of conditional inference. More research will be needed to determine the extent to which people conform to 
any general tables, and to discover which conditional inferences they do endorse. Our object here has been to argue that this research should be done and to explain one way to do it.

The experimental pillars supporting the new paradigm in the psychology of reasoning are two findings for the indicative conditional, if $A$ then $B$, of natural language. First, that people comply with the Equation, by judging $P($ if $A$ then $B)=P(B \mid A)$, which is implied by the Ramsey test. Second, that people conform to the restricted de Finetti table for if $A$ then $B$. However, the new paradigm is in the early stages of its development, and there is much to do to investigate and extend these findings. In this paper, we have shown how to extend research to general de Finetti tables and their interpretation, and have argued for the importance of taking this step. 


\section{References}

Adams, E. 1998: A Primer of Probability Logic. Stanford: CLSI publications.

Beaver, D. 1997: Presupposition. In J. van Benthem and A. T. Meulen (eds.), Handbook of Logic and Language (pp.939-1008). Amsterdam: Elsevier Science Publishers.

Blamey, S. 1986: Partial logic. In D. Gabbayand F. \& Guenthner (eds), Handbook of Philosophical Logic, Vol. 3 (pp. 1-70). Dordrecht: Reidel.

Bonnefon, J. F. 2009: A theory of utility conditionals: Paralogical reasoning from decisiontheoretic leakage. Psychological Review, 118, 888-907.

de Finetti, B. 1936/1995: The logic of probability. Translated in R. B. Angell, The logic of probability. Philosophical Studies, 77, 181-190.

de Finetti, B. 1937/1964: Foresight: Its logical laws, its subjective sources. Translated in H. Kyburg \& H. E. Smokier (eds), Studies in Subjective Probability (pp. 55-118). New York: Wiley.

de Finetti, B. 1974: Theory of Probability. Vol. 1. Chichester: Wiley.

Douven, I., \& Dietz, R. 2011: A puzzle about Stalnaker's hypothesis, Topoi, 30, 31-37.

Douven, I., \& Verbrugge, S. 2010: The Adams family. Cognition, 117, 302-318.

Douven, I., \& Verbrugge, S. (in press). Indicatives, concessives, and evidential support. Thinking \& Reasoning.

Douven, I., \& Verbrugge, S. (under review). The probabilities of conditionals revisited.

Edgington, D. 1995: On conditionals. Mind, 104, 235-329.

Evans, J. St. B. T. 2012: Questions and challenges for the new psychology of reasoning. Thinking \& Reasoning, 1, 5-31.

Evans, J. St. B. T., Handley, S., Neilens, H., \& Over, D. E. 2007: Thinking about conditionals: A study of individual differences. Memory \& Cognition, 35, 1772-1784. 
Evans, J. St. B. T., Handley, S. J. , \& Over, D. E. 2003: Conditionals and conditional probability. Journal of Experimental Psychology: Learning, Memory, and Cognition, 29, 321-335.

Evans, J. St. B. T., \& Over, D. E. 2004: If. Oxford: Oxford University Press.

Evans, J. St. B. T. \& Over, D. E. 2010: Conditional truth: Comments on Byrne and JohnsonLaird. Trends in Cognitive Sciences, 14, 5.

Fugard, J. B., Pfeifer, N., Mayerhofer, B., \& Kleiter, G. 2011: How people interpret conditionals: Shifts towards the conditional event. Journal of Experimental Psychology: Learning, Memory, and Cognition, Vol. 37, No. 3, 635-648.

Gauffroy, C., Barrouillet, P. 2009: Heuristic and analytic processes in mental models for conditionals: An integrative developmental theory. Developmental Review, 29, 249282.

George, C. 1995: The endorsement of the premises: assumption based or belief-based reasoning. British Journal of Psychology, 86, 93-111

George, C. 1997: Reasoning from uncertain premises. Thinking \& Reasoning, 3, 161-189

Gilio, A., \& Over, D. E. 2012: The psychology of inferring conditionals from disjunctions and its probabilistic analysis. Journal of Mathematical Psychology, 56, 118-131.

Goodman, I. R., Nguyen, H. T., \& Walker, E. 1991: Conditional Inference and Logic for Intelligent Systems: A Theory of Measure-Free Conditioning. Amsterdam: NorthHolland.

Haack, S. 1974: Deviant logic. Cambridge: Cambridge University Press.

Hahn, U., \& Oaksford, M. 2007: The rationality of informal argumentation: A Bayesian approach to reasoning fallacies. Psychological Review, 114, 704-732. 
Lewis, D. 1986: Probabilities of conditionals and conditional probabilities. In D. Lewis, Philosophical Papers. (pp. 133-156). Oxford: Oxford University Press.

Manktelow, K. I., Over, D. E., \& Elqayam, S. 2011: Paradigms shift: Jonathan Evans and the science of reason. In K. I. Manktelow, D. E. Over, \& S. Elqayam (eds), The Science of Eeason: A Festschrift for J. St. B. T. Evans. Hove: Psychology Press.

Milne, P. 1997. Bruno de Finetti and the logic of conditional events. The British Journal for the Philosophy of Science, 48, 195-232.

Milne, P. 2012: Indicative conditionals: a request for more experiments. Thinking \& Reasoning, 18, 196-224.

Mura, A. 2009: Probability and the logic of de Finetti's trievents. In M. C. Galavotti (Ed.), Bruno de Finetti Radical Probabilist (pp.201-242). London: College Publications.

Oaksford, M., \& Chater, N. 2007: Bayesian Rationality: The Probabilistic Approach to Human Reasoning. Oxford: Oxford University Press.

Oaksford, M., \& Chater, N. 2009: Précis of Bayesian rationality: The probabilistic approach to human reasoning. Behavioral and Brain Sciences, 32, 69-84.

Oberauer, K., \& Wilhelm, O. 2003: The meaning(s) of conditionals: Conditional probabilities, mental models and personal utilities. Journal of Experimental Psychology: Learning, Memory and Cognition, 29, 688-693.

Over, D. E. 2009: New paradigm psychology of reasoning. Thinking \& Reasoning, 15, 431438.

Over, D. E., Evans, J. St. B. T., \& Elqayam, S. 2010: Conditionals and non-constructive reasoning. In M. Oaksford \& N. Chater (eds), Cognition and Conditionals: Probability and Logic in Human Thinking (135-151). Oxford: Oxford University Press. 
Over, D. E., Hadjichristidis, C., Evans, J. St. B. T., Handley, S. J., \& Sloman, S. A. 2007: The probability of causal conditionals. Cognitive Psychology, 54, 62-97.

Paneni, T., \& Scozzafava R. 2003: Multi-valued conditional events avoid Lewis' triviality result. In T.D. Nielsen \& N.L. Zhang (eds), Symbolic and Quantitative Approaches to Reasoning with Uncertainty. Lecture Notes in Computer Science, Vol. 2711 (pp. $432-$ 439). Berlin: Springer.

Pfeifer, N., \& Kleiter, G. D. 2010: The conditional in mental probability logic. In M. Oaksford \& N. Chater (eds), Cognition and Conditionals: Probability and Logic in Human Thinking (pp. 153-173). Oxford: Oxford University Press.

Politzer, G. 2005: Uncertainty and the suppression of inferences. Thinking \& Reasoning, 11, $5-33$.

Politzer, G., Over, D. E., \& Baratgin, J. 2010: Betting on conditionals. Thinking \& Reasoning, 16, 172-197.

Politzer G, \& Bourmaud, G. 2002: Deductive reasoning from uncertain conditionals. British Journal of Psychology, 93, 345-381

Ramsey, F. P. (1926/1990). Truth and probability. In D.H. Mellor (ed.), Philosophical Papers (pp. 52-94). Cambridge: Cambridge University Press.

Ramsey, F. P. 1929/1990: General propositions and causality. In D.H. Mellor (ed.), Philosophical Papers (pp. 145-163). Cambridge: Cambridge University Press.

Sevenants, A., Dieussaert, K., \& Schaeken, W. 2011: Truth table tasks: Irrelevance and cognitive ability. Thinking \& Reasoning, 17, 213-246.

Stalnaker, R.C. 1968: A theory of Conditional. In N. Rescher(ed.), Studies in Logical Theory (pp. 98-112). Oxford: Basil Blackwell.

Stevenson, R. and D. Over 1995: Deduction from uncertain premises. The Quarterly Journal of Experimental Psychology, Section A, 48, 613-643. 
Stevenson, R. and D. Over 2001: Reasoning from Uncertain Premises: The Effects of Expertise and Conversational Context. Thinking and Reasoning, 7, 367-390.van Fraassen, B.C. 1976: Probabilities of conditionals. In W.L. Harper and C.A. Hooker (eds.), Foundations of Probability Theory, Statistical Inference, and Statistical Theories of Science (vol.1, pp. 261-301), Dordrecht: Reidel. 


\section{Appendix 1}

The three-valued tables of de Finetti (1936/1995), but we have used U here for 'uncertain'.

Negation

\begin{tabular}{|l|l|}
\hline $\mathrm{A}$ & $\neg \mathrm{A}$ \\
\hline $\mathrm{T}$ & $\mathrm{F}$ \\
\hline $\mathrm{U}$ & $\mathrm{U}$ \\
\hline $\mathrm{F}$ & $\mathrm{T}$ \\
\hline
\end{tabular}

Conjunction

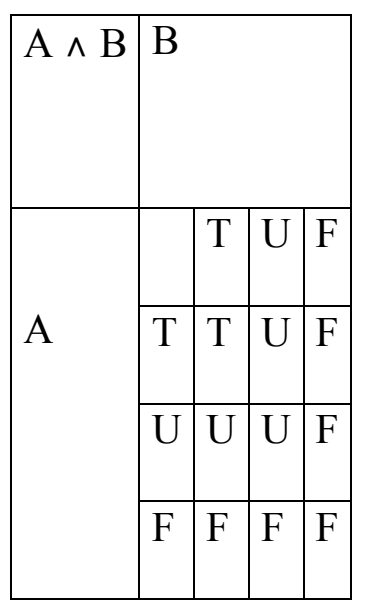

Disjunction

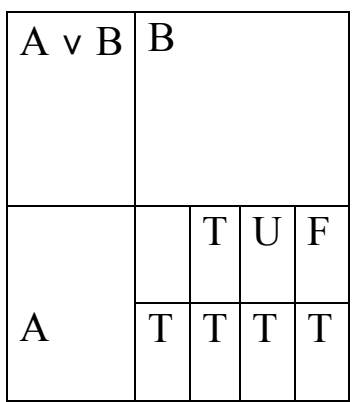




\begin{tabular}{|l|l|l|l|l|}
\hline & $\mathrm{U}$ & $\mathrm{T}$ & $\mathrm{U}$ & $\mathrm{U}$ \\
& $\mathrm{F}$ & $\mathrm{T}$ & $\mathrm{U}$ & $\mathrm{F}$ \\
\hline
\end{tabular}


Conditional event

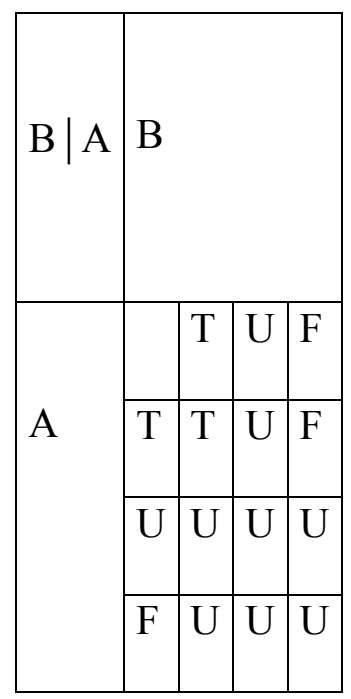

Material conditional

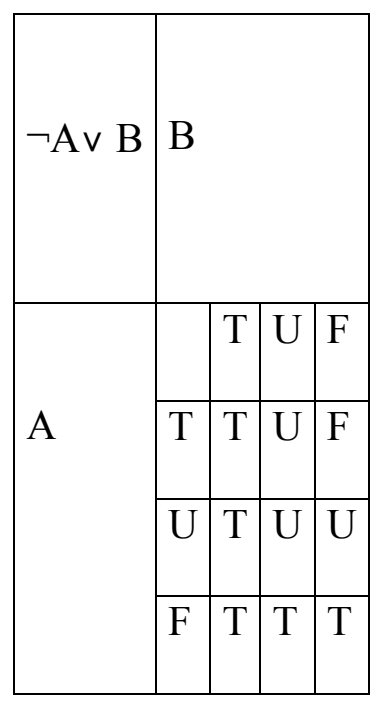


Jean Baratgin

CHART (PARIS, University of Paris 8 \& EPHE) \& Institut Jean Nicod

David E. Over

Psychology

Durham University

Guy Politzer

Institut Jean Nicod

Paris, France

4096 words 